\title{
SPRING PHENOPHASES IN RECENT DECADES OVER EASTERN CHINA AND ITS POSSIBLE LINK TO CLIMATE CHANGES
}

\author{
JINGYUN ZHENG ${ }^{1,2}$, QUANSHENG GE ${ }^{1}$, ZHIXIN HAO ${ }^{1,2}$ \\ and WEI-CHYUNG WANG ${ }^{2}$ \\ ${ }^{1}$ Institute of Geographical Sciences and Natural Resources Research, \\ Chinese Academy of Sciences, Beijing 100101, China \\ E-mail: zhengjy@igsnrr.ac.cn \\ ${ }^{2}$ Atmospheric Sciences Research Center, State University of New York, Albany, NY 12203, USA
}

\begin{abstract}
In light of the observed climate changes in recent decades over eastern China, we studied the changes in spring phenophases of woody plants observed at 16-stations during 1963-1996, and explored the possible link between the spring phenophases changes and climate changes before the phenophase onset. It is found that, in the region north of $33^{\circ} \mathrm{N}$ (including Northeast, North China and the lower reaches of the Huaihe River), the phenophase advanced 1.1-4.3 days per decade for early spring and 1.4-5.4 days per decade for late spring, but in the eastern part of the southwest China it was dealyed by 2.9-6.9 days per decade in early spring and 2.4-6.2 days per decade in late spring. One outstanding feature is identified in Guangzhou in south China, where significant advance of 7.5 days per decade in early spring and delay of 4.6 days per decade in late spring were detected. Statistically siginficant correlation was found between the changes of spring phenophase and the temperatures of one or several months before the phenophase onset. The relationship between the trend of phenophase change and temperature change was highly nonlinear (more sensitivity to cooling than to warming) and reached an asymptote $0.5^{\circ} \mathrm{C}$ per decade, which may have implication in the responses of the ecosystem in a future global warming scenario. In addition, we also examined the link between the spring phenophase, and length and mean temperature of the growing season, and the analyses suggested that they were highly correlated as well.
\end{abstract}

\section{Introduction}

Phenology is the study of the timing of periodic biological events, and their relationship with the environment, especially climate (Lieth, 1974). The cycle of phenological events (such as flowering, fruiting, leaf falling), is not only used to define annual seasonal sequences and other relevant applications (Lieth and Schwartz, 1997), but also to measure the response of plant systems to changes in temperature, particularly in recent surface warming (IPCC, 2001).

Numerous studies have indicated that the phenophase has changed in many regions around the world, for example, the advance of spring phenophase, the delay of autumn phenophase, and birds laying eggs earlier (Crick et al., 1997; Menzel and Fabian, 1999; Peñuelas and Filella, 2001; Both and Visser, 2001) due to surface warming. In particular, the rising spring temperatures during the past century have advanced the timing of leafing and flowering in many species at 
high northern latitudes in both Europe (Chmielewsky and Roetzer, 2001; Peñuelas et al., 2002) and North America (Schwartz and Reiter, 2000; Bradley et al., 1999; Abu-Asab et al., 2001; Beaubien and Freeland, 2000). Recently, Parmesan and Yohe (2003) developed databases suitable for meta-analysis on two phenomena: range-boundary changes and phenological shifts of plants over time periods of 16-132 years (median 45 years). Global meta-analyses documented significant range shifts averageing $6.1 \mathrm{~km}$ per decade towards the poles, and significant mean advancement of spring events by 2.3 days per decade, both strongly suggest that climate change has already affected living systems. A review paper by Walther (2004) concluded that the response of different species and/or at different locations may be uneven. Such differences in the phenological response to climate warming may result from the variabilities of the taxa included in the studies, the seasonal variations of surface warming, and the geographic distribution of data collected. It is also apparent that the length, starting and ending dates of the observational data are critical in determining the signal. However, despite the inadequacy in the data used, the overall indication of an earlier onset of spring in northern mid-latitudes is evident.

There have been many studies in changes in spring phenophase of recent decades in China. For example, Chen and Zhang (2001) reported that, in Beijing, the first bloom of peach (Prunus davidina Franch) and lilac (Syringa oblata Lindl), blossom of acacia (Robinia pseudoacacia L.) showed an advance trend since 1985, especially during 1990s. In the central part of northern monsoon region in China, a lengthening of the growing season had been detected from 1982 to 1993 (Chen et al., 2000, 2001). However, although the last spring frost dates over China became markedly earlier with the greatest change occurring in the Northeast China, the onset of spring plants growth showed no apparent change during 1959-1993 (Schwartz and Chen, 2002). Zheng et al. (2002) showed a spatial pattern of spring phenology change, advanced in Northeastern China, North China and the lower reaches of the Yangtze River, and delayed in the eastern part of Southwestern China and the middle reaches of the Yangtze River since the 1980s. Because the surface warming in China exhibited "more in the winter" and "larger in the north" (Sha et al., 2002), the winter warming may have larger impact on growth and development of plant and crop, especially when winter warming decreases the number of days in frost condition (Scheifinger et al., 2003). Therefore, the lengthening of the growing season could be attributed more to the advances of spring phenophases than to the delay in the autumn (Menzel et al., 2003). Consequently, in addition to summarizing the change of spring phenophases of woody plants in eastern China, here we also analyze the relationship of the phenophase change with the temperature change before the onset of individual phenophase in spring time. Note that this study adds two more stations, and includes additional species for several stations when compared with Zheng et al. (2002). 


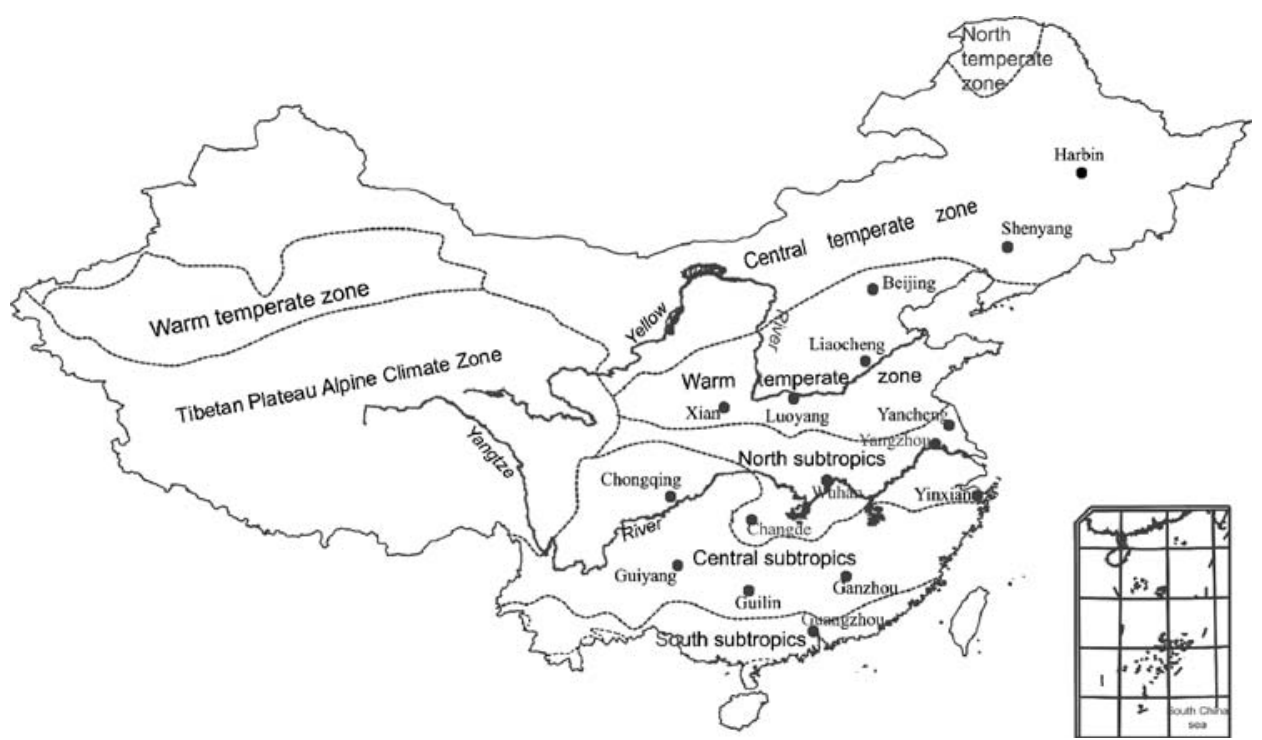

Figure 1. The location for 16-stations and climatic zone (From Edit committee of Atlas of People's Republic of China, 1984).

\section{Changes in Spring Phenophase and its Relationship to Temperature in Springtime}

There were more than 60 phenological observation stations in China. However, most of them are located in eastern China. Except for the Beijing station where the records existed for 1950-2000, most of other stations have data during 19631996; however the 1968-1971 data were not available (Zhang and Jiang, 1996). In this study, after considering the record length and spatial distribution (Table I), we choose 16-stations. And their location and climatic zones (Edit committee of Atlas of People's Republic of China, 1984) are illustrated in Figure 1. For each station, two species and their phenophases were selected, which represented early-spring and late-spring, based on the natural phenological calendar for each station (Wan, 1986, 1987). The relevant characteristics are described below.

\subsection{TREND AND ITS SPATIAL PATTERN}

The phenophases of the 16 stations were shown in Figure 2. To present the trend of spring phenophase for individual station, regression analysis commonly used in phenology studies (Bradley et al., 1999) was adopted to calculate the linear slope of the yearly records for each phenophase (Table I). In addition, we also reported the $t$ value (Student's $t$ distribution), and the $p$ value (a measure of the statistical significance of fitting to the regression line). Table I indicates that changes of the 


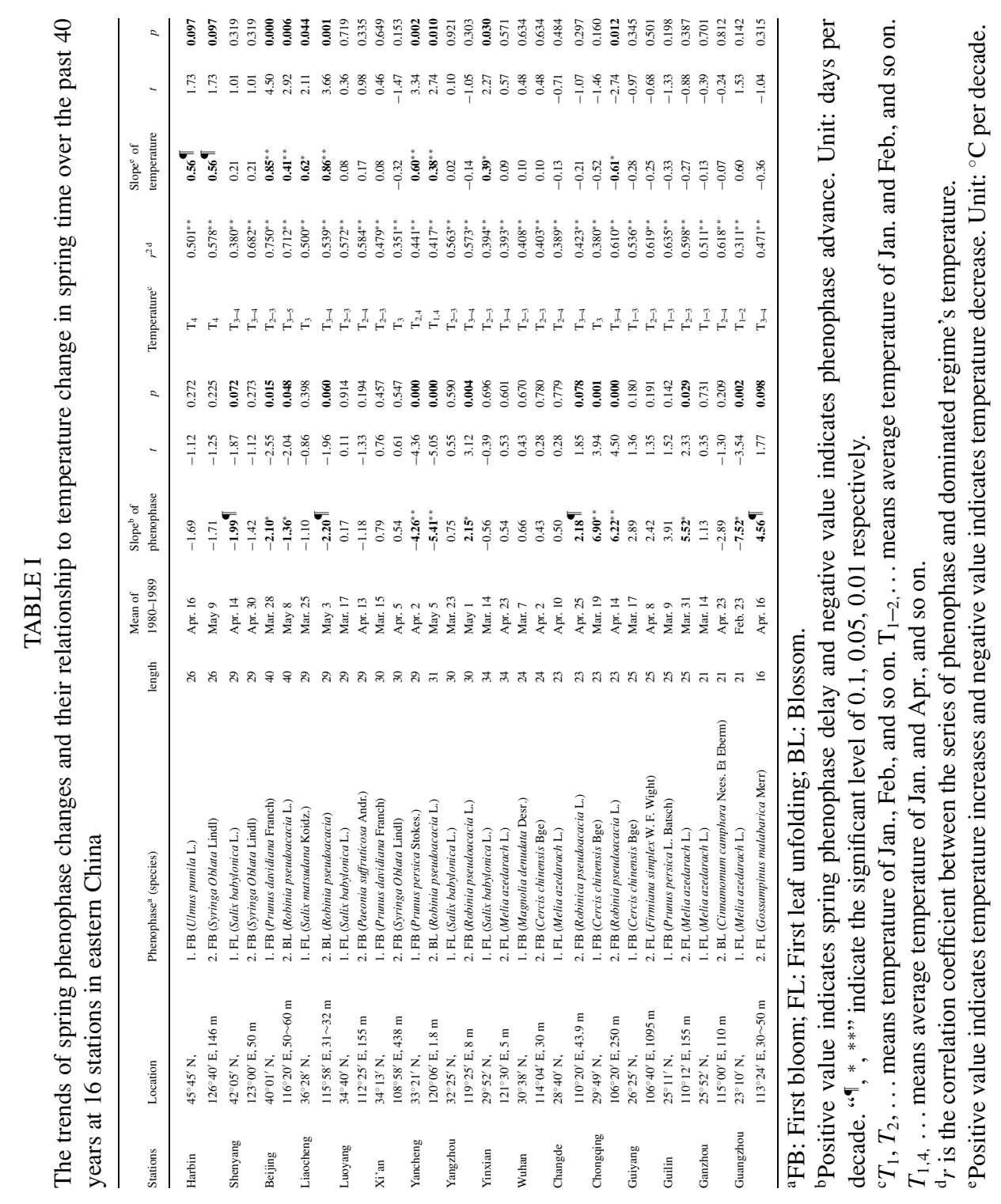


SPRING PHENOPHASES AND CLIMATE CHANGES IN RECENT DECADES OVER CHINA 453

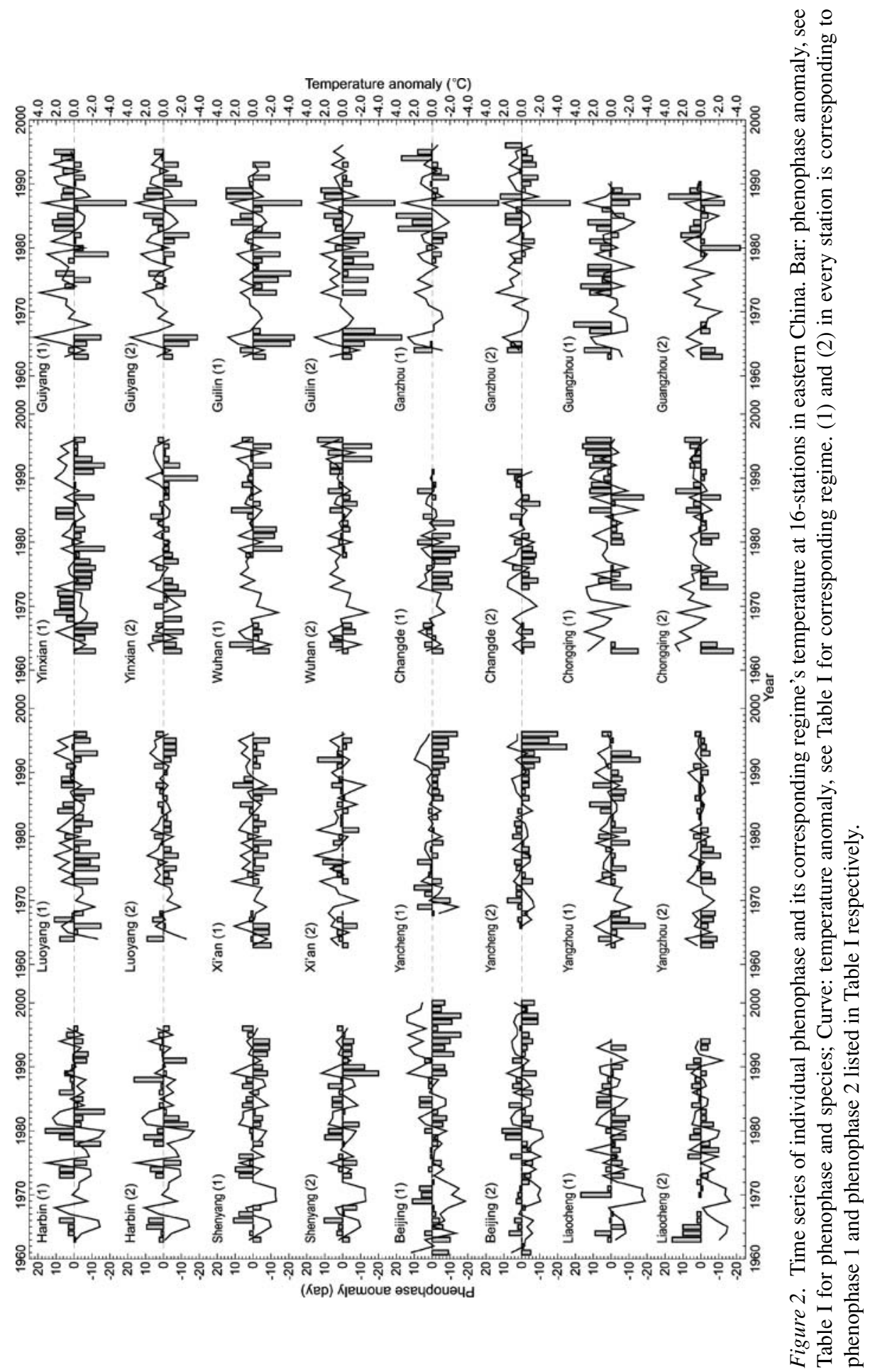


32 phenophases in 16 stations showed: 13 significant changes (seven advanced and six delayed), 11 slightly ( $t$ value between +1.0 and -1.0 ), and the remaining 8 changes but not statistically significant (5 advanced with $73-80 \%$ probability and the other 3 delayed with $81-86 \%$ probability).

The "advance, no trend, and delay" of the 32 phenophases can be associated with different geographical zones. The spring (including early and late spring) phenophases advanced in the Northeast China (Harbin and Shenyang), North China (Beijing and Liaocheng) and the lower reaches of the Huaihe River (Yancheng). Of the total 10 phenophases, six advanced significantly with more than $90 \%$ probability, and 3 with more than $70 \%$ probability and 1 with a $60 \%$ probability. The maximum phenophase advance rate, occurred at Yancheng, was about 4.3 days per decade and 5.4 days per decade, respectively, for the early and late spring. The minimum phenophase advance rate was found at Liaocheng and Beijing with value of 1.1 days per decade and 1.4 days per decade respectively for the early and late spring. Note that the values of advance trends (1.1-4.3 days per decade in early spring and 1.4-5.4 days per decade in late spring) are consistent with 1.2-3.8 days per decade (on average) identified in Europe and North America (Dose and Menzel, 2004).

However, regions in Central China (Xi' an and Luoyang) and the middle and lower reaches of the Yangtze River (Changde, Wuhan, Yangzhou, Yinxian and Ganzhou) did not show a clear trend in the spring phenophase: most of the values were less than 1.0 day per decade. Ten of the 14 phenophases indicated either advance or delay with $t$ value between +1.0 and -1.0 , while two (in late spring for Luoyang and Ganzhou) advanced with $80 \%$ probability, and two (in late spring for Changde and Yangzhou) delayed with $90 \%$ probability.

Meanwhile, the spring phenophase delayed both in early and late spring in Chongqing, Guilin and Guiyang, located in the eastern part of the Southwest China. The maximum phenophase delay rate occurred in Chongqing with value of 6.9 days per decade in early spring and 6.2 days per decade in late spring, and the minimum phenophase delay rate was found in Guiyang with 2.9 days per decade in early spring and 2.4 days per decade in late spring. The regression slopes for 3 of the 6 phenophases delayed significantly with more than $97 \%$ probability, and another 3 phenophases delayed with more than $80 \%$ probability. Moreover, the phenophase advanced in the early spring with value of 7.5 days per decade $(\alpha=0.01$ significance level), but delayed in late spring with 4.6 days per decade $(\alpha=0.10$ significance level) at Guangzhou located in South China.

\subsection{TEMPERATURE REGIME AND SPRING PHENOPHASE ONSET}

It is known that there exists a strong connection between the onset of phenophase of individual plants and temperature (Lieth, 1974). However, the connection depends highly on the temperature regime, which is sensitive to the regions under consideration. To demonstrate this issue, the stepwise correlation analysis between 
the individual phenophase series and monthly temperature series was used for each station, and the results are also given in Table I.

Table I indicated that the individual phenophase was well related either to the monthly mean temperature of that month or to several months before the phenophase appears, and sometimes to both. For example, the average date of first bloom for Prunus davidiana Franch was March 28 in Beijing, which was closely related to the temperature of March and February; the average date of blossom for Robinia pseudoacacia L. was May 8, and the series of blossom for Robinia pseudoacacia $\mathrm{L}$. had a good relationship with the temperature in April, March and May. The mean date of the first bloom for Ulmus pumila L. and Syringa Oblata Lindl at Harbin was April 16 and May 9 respectively, and both were well related to the temperature of April. However, at Yancheng, the mean date of first bloom for Prunus persica Stokes and blossom for Robinia pseudoacacia L. was April 2 and May 5 respectively, which was closely related not only to the temperature of April, but also to that of February and January, respectively. This is because the spring phenophases of individual plants are mainly triggered by the seasonal temperature regime, including not only the magnitude of temperature, but also the accumulated temperature, as well as the low temperature before certain phenophase for some plant vernalization (Chu and Wan, 1973; Zhang, 1985). In other words, the onset depends not only on the threshold temperature but also the temperatures during the transition from winter to spring; the latter therefore implies that the identical species (or phenophases) at different locations would have different temperature associations. For example, the species will be more sensitive to the threshold temperature at Harbin (located in the Northeast with shorter transition) than the places further south where the accumulated temperatures will play more important role.

\subsection{RELATIONSHIP BETWEEN TRENDS OF PHENOPHASE CHANGE AND CORRESPONDING TEMPERATURE REGIME CHANGE}

In Table I, we listed the slopes of dominated temperature regime series and their $t$-value and $p$-value corresponding to 32 phenophases series from the 16 stations. The dominated temperatures regime for most stations increased significantly in Northeast China, North China and the lower reaches of the Huaihe River. For Central China, and the middle and lower reaches of the Yangtze River, most stations showed a slight increasing temperature trend with several indicated a weak decreasing trend, although both did not pass significance test. However, at Chongqing, located in the eastern part of the Southwest China, the dominated temperature regime experienced a significant cooling trend. At Guangzhou of South China, the temperature increased in January and February, but decreased in March and April. Because the response of recent biological trends to climate change was complicated (see Parmesan and Yohe, 2003), not all the trends in phenophases and temperature were coherent. For example, at Wuhan, the slope of temperature showed a very small warming 


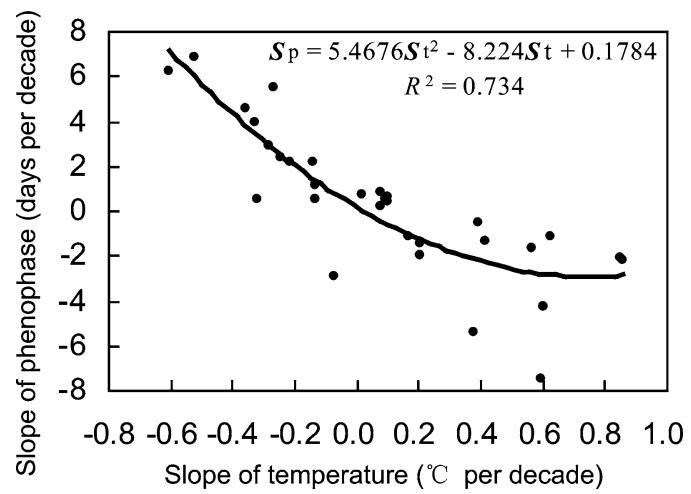

Figure 3. Diagram of the slopes between individual phenophase series and its corresponding dominated temperature regime.

trend, but the phenophase exhibited a small delay trend; at Ganzhou, the slope of temperature showed a very small cooling trend, but the phenophase exhibited an advance trend.

A closer examination of the slope of phenophases changes with temperature changes showed an interesting characteristic: the slope of increasing temperature was relatively larger in warming areas (the Northeast, North China, and the lower reaches of the Huaihe River) versus the slope in cooling areas (the eastern region of Southwest China and the middle reaches of the Yangtze River), but on average, the slope of phenophase delayed in cooling areas was greater than the slope of phenophase advance in warming areas. Analyzing the diagram (Figure 3) of the slopes of individual phenophase and its corresponding dominated temperature regime, a non-linear regression equation could be obtained,

$$
\mathbf{S}_{p}=5.4676 \mathbf{S}_{t}^{2}-8.224 \mathbf{S}_{t}+0.1784,
$$

where $\mathbf{S}_{p}$ is the slope of phenophase (days per decade), and $\mathbf{S}_{t}$ is the slope of key regime temperature $\left({ }^{\circ} \mathrm{C}\right.$ per decade). The correlation coefficient is 0.857 , indicating statistically significant at 0.001 level. This equation demonstrated that the spring phenophase change was more sensitive to cooling than to warming. Causal attribution of this phenomenon is likely to be that the cooling would result in higher probability of cold injury (such as last frost), which leads to higher probability of discontinuity for plant development, thus required more time to reset (Zhang, 1985).

Figure 3 also shows that when the slope of temperature increase was less than $0.5^{\circ} \mathrm{C}$ per decade, spring phenophase advances corresponding to temperature increases. While the slope of temperature increase was more than $0.5^{\circ} \mathrm{C}$ per decade, the slope of spring phenophase was close to invariant. This implies that there exists a threshold for the response of spring phenology to surface warming in Eastern China, which was about $0.5^{\circ} \mathrm{C}$ per decade. The reason why there 
is a threshold of response of plant phenophase to climate change is that each plant has its ecological adaptive ability with ranges of tolerance to environmental factors. If climate warming exceeds the plant range of tolerance, its phenophase could not adapt to such change and may shift to area of higher altitude or latitude (IPCC, 2001).

\section{The Connection of Changes in Spring Phenophase and Characteristics of Growing Season}

During the last few years, many studies have revealed a lengthening of the growing season across the Northern Hemisphere attributed to surface warming, thus providing an important indicator of climate change (Myneni et al., 1997; Menzel et al., 2001; Walther et al., 2002; Root et al., 2003). The lengthening of the growing season usually can be attributed to the advancement of spring phenology (Menzel and Fabian, 1999). However, Schwartz and Chen (2002) concluded that the onset of spring plant growth had no apparent trend during 1959-1993, although the last spring frost dates over China became markedly earlier in the Northeast China. Below we present an analysis of a possible connection between changes in spring phenophases and the length, and mean temperature and precipitation during growing season.

\subsection{SPATIAL DISTRIBUTION OF GROWING SEASON LENGTH}

The growing season is usually defined by the number of days between the last freeze in the spring and the first frost in the fall. Therefore, growing season varies, depending on the geographical location and the associated climate regime. It can also vary by plants, as different plant species have different freezing temperature thresholds. Since most woody plants do not grow vegetatively when daily mean temperature is less than $10^{\circ} \mathrm{C}$ (Seemann et al., 1979), we define the growing season as the period between the first and last occurrence of steady (i.e. at least for 5 consecutive days) daily mean temperature $T \geq 10^{\circ} \mathrm{C}$. In the analysis, we identified the first and last occurrence dates based on the daily mean temperatures, and then calculated the length and mean temperature of growing season for each year. The 30years mean value of growing season length from 1961-1990 was used as reference. Note that we used the climatological daily mean temperature and precipitation observed at 158 stations over China.

Figure 4 presented the mean length of growing season for 1961-1990, which showed a zonal orientation in eastern China with a maximum of more than 360day in the south and a minimum of 140-day in the northeast. However, in western China, the isoclinic line of growing season length was less zonal with maximum in Xinjiang Province and minimum in Qinghai-Tibetan Plateau. 


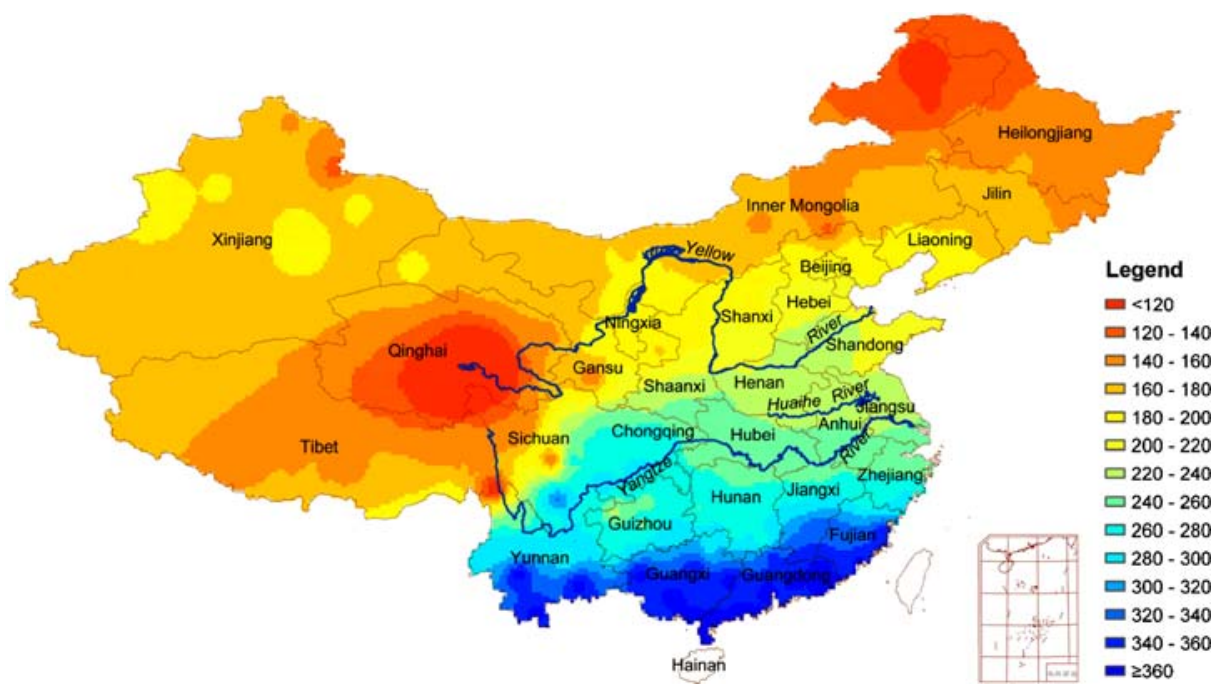

Figure 4. Mean length of growing season for 1961-1990.

\subsection{CONNECTION BETWEEN CHANGES OF SPRING PHENOPHASES AND MEAN TEMPERATURE DURING GROWING SEASON}

The deviations (from the 1961-1980 means) of the 1981-2000 averaged length and mean temperature of growing season were shown in Figure 5. For comparison purpose, we also plotted the slope of spring phenophase. The comparisons indicate that the pattern of phenophase change trend appears to be consistent with that of the change of growing season length and temperature during growing season. After 1980, the growing season lengthened in Northeast China and North China with the maxima increased by more than 6 days around Beijing and Shenyang (Figure $5 \mathrm{a}$ ); and in most of this area, the growing season temperature increased $0.3-0.9^{\circ} \mathrm{C}$ (Figure 5b). For example, in Beijing and around area, it increased $0.6-0.9^{\circ} \mathrm{C}$, which exhibited the largest increases over China. Meanwhile, the spring phenophases in Harbin, Shenyang, Beijing and Liaocheng showed a clear advanced trend of 1.1-2.2 days per decade since 1961 .

In most areas between the Yellow River and the Yangtze River which cover the Central China and the eastern part of Southwest China, the growing season shortened with a maximum decrease of more than 6-days near Chongqing and the boundary area of Shaanxi, Henan and Hubei Provinces. The growing season temperature decreased in the eastern part of Southwest China with a maximum decrease near Chongqing, and the spring phenophases of Chongqing and Changde showed a significant delay trend. In other regions of this area, the growing season showed a slight warming less than $0.3^{\circ} \mathrm{C}$, and the spring phenophases of Xi'an, Luoyang, Wuhan and Yangzhou did not show 

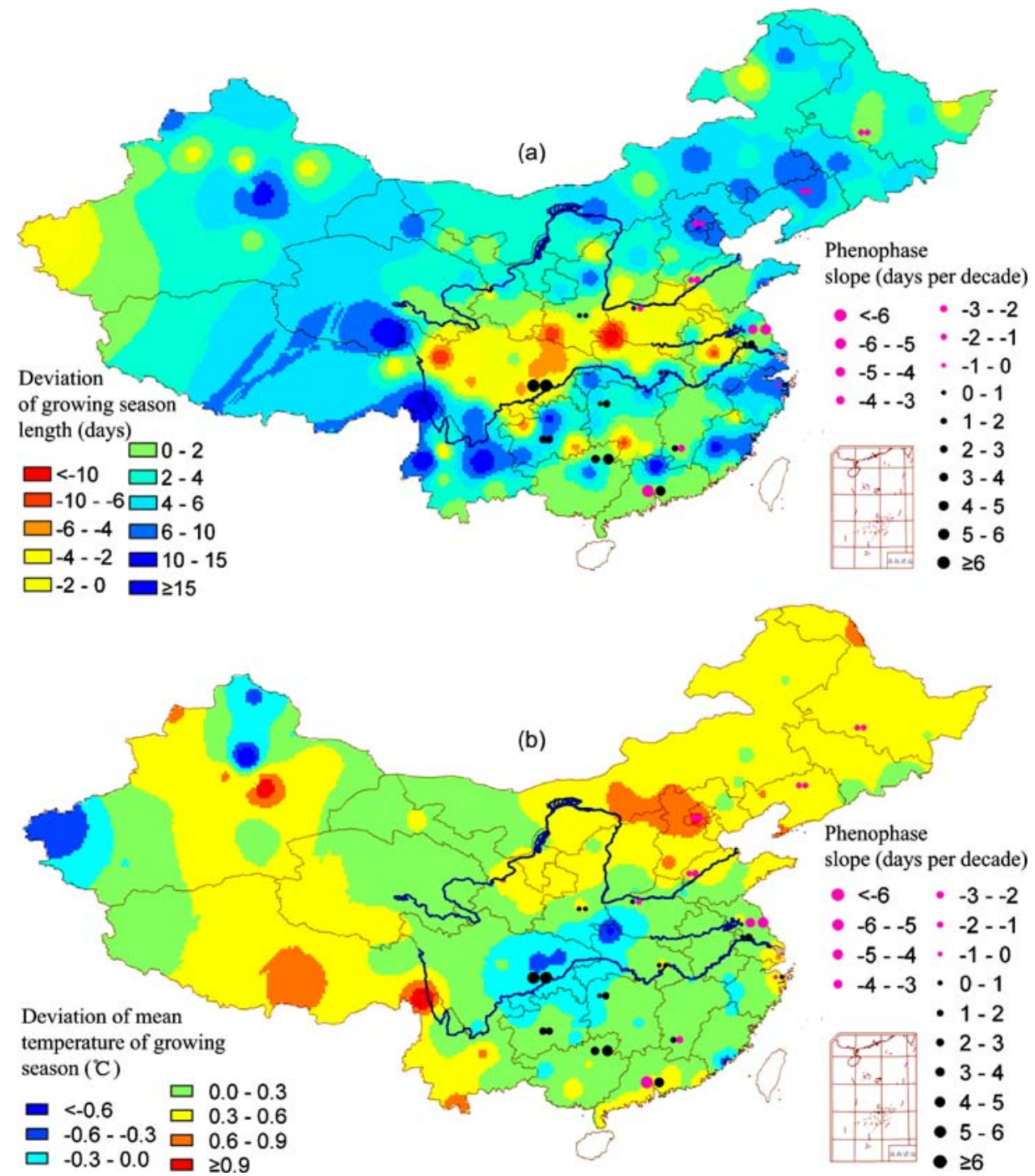

Figure 5. Spatial patterns for the changes of the length and mean temperature during the growing season and comparison with regional difference for change trend in springtime. (a) The deviation from 1961-1980, of the 1981-2000 averaged length of growing season. (b) The deviation from 1961-1980, of the 1981-2000 averaged mean temperature of growing season.

significant trends statistically, except for a significant advance trend occurred in Yancheng.

In the south of Yangtze River, most areas showed an increasing trend in growing season length, except that in the boundary area of Guizhou, Hunan and Guangxi Provinces, i.e. the area near Guiyang and Guilin where it was shortened; and most areas experienced a slight warming in growing season with magnitude less than 
$0.3^{\circ} \mathrm{C}$, except for a little high warming around Yinxian and Guangzhou. While the spring phenophases of Guiyang and Guilin showed a delay trend, and the spring phenophases of Yinxian and Ganzhou did not exhibit a significant change statistically. Meanwhile, the phenophase of early spring in Guangzhou showed a significant advance trend, in response to a warming of the growing season temperature.

In addition, we also examined the connection between changes of phenophases and precipitation in springtime, but the relationship is not statistically significant. Comparisons of the patterns of spring phenophases change trend with the pattern of precipitation difference were not conclusive.

\section{Concluding Remarks}

This study used observations to document the change of spring phenophases of woody plants in eastern China, and its possible link to climate change in China. It is found that the advance trends in phenophases occurred mainly in northern regions in both early and late spring, which were in line with the observed warming of the climate, and opposite changes were detected in the southwestern regions, in consistent with a cooling trend. In addition, changes in spring phenophases were also qualitatively consistent with changes of the growing season, in agreement with earlier studies (e.g., Peñuelas and Filella, 2001). Nevertheless, the changes of the length and mean temperature during growing season were not totally consistent, e.g., in the upper valley of Huaihe River, the growing season length shortened but mean temperature increased slightly. While in Guiyang and Guilin, the temperature in springtime decreased, and the spring phenophase delayed; however the growing season lengthened and mean temperature during growing season increased. This is because that the feature of growing season lengthening and warming not only mainly attributed to the advance of spring onset, but also related to the delay of the ending date in fall; the growing season warming is affected by summer temperature change as well.

The study results of less sensitivity of spring phenophase to a warming climate may have significant implication in a future global warming scenario. However, the non-linear response of phenophase to temperature change was based on integrating over the whole eastern China, which involved different species from different sites. Further study considering individual species at different climate zones is warranted. In addition, the connection between changes of spring phenophases and a combined change in temperature and precipitation needs to be addressed in more details, perhaps using daily temperature and precipitation information. Moreover, analysis of the sensitivity of growing season lengthening to the onset in spring, warming in summer during growing season, and delay in fall as well as to the cooling trends found in several stations should be conducted. 


\section{Acknowledgements}

This study was supported by the National Natural Science Foundation of China (Grant No. 40371019), the Chinese Academy of Sciences (Grant No. KZCX3-SW321). Part of the research was conducted when JZ and ZH were visiting SUNYA under the sponsorship of U.S. Department of Energy-P.R.C. Ministry of Science and Technology agreement, 'Climate Sciences'.

\section{References}

Abu-Asab, M. S., Peterson, P. M., Shetler, S. G., and Orli, S. S.: 2001, 'Earlier plant flowering in spring as a response to global warming in the Washington, DC, area', Biodiversity and Conservation 10, 597-612.

Beaubien, E. G. and Freeland, H. J.: 2000, 'Spring phenology trends in Alberta, Canada: Links to ocean temperature', Int. J. Biometeorol. 44, 53-59.

Both, C. and Visser, M. E.: 2001, 'Adjustment to climate change is constrained by arrival date in a long-distance migrant bird', Nature 411, 296-298.

Bradley, N. L., Leopold, A. C., Ross, J., and Wellington, H.: 1999, 'Phenological changes reflect climate change in Wisconsin', Proc. Natl. Acad. Sci. USA 96, 9701-9704.

Chen, X., Tan, Z., Schwartz, M., and Xu, C.: 2000. 'Determining the growing season of land vegetation on the basis of plant phenology and satellite data in Northern China', International Journal of Biometeorology 44, 97-101.

Chen, X., Xu, C., and Tan, Z.: 2001, 'An analysis of relationships among plant community phenology and season metrics of Normalized Difference Vegetation Index in the northern part of the monsoon region of China', International Journal of Biometeorology 45, 170-177.

Chen, X. and Zhang, F.: 2001, 'Spring phenological Change in Beijing in the Last 50 years and its response to the climate changes', Chinese Journal of Agrometeorology 22, 1-5 (in Chinese).

Chmielewsky, F. M. and Roetzer, T.: 2001, 'Responses of tree phenology to climate change across Europe', Agr. Forest Meteorol. 108, 101-112.

Chu, K.-C. and Wan, M.: 1973, Phenology, Beijing, Science Press, pp. $35-39$ (in Chinese).

Crick, H. Q. P., Dudley, C., Glue, D. E., and Thomson, D. L.: 1997, 'UK birds are laying eggs earlier', Nature 388, 526.

Dose, V. and Menzel, A.: 2004, 'Bayesian analysis of climate change impacts in phenology', Glob. Change Biol. 10, 259-272.

Edit committee of Atlas of People's Republic of China: 1984, Atlas of People's Republic of China, The Sinomap Press, Beijing, p. 12 (in chinese).

Intergovernmental Panel on Climate Change (IPCC): 2001, Climate Change 2001: Impacts, Adaptation, and Vulnerability, Cambridge University Press, Cambridge, UK and New York, USA, pp. 244-252.

Lieth, H. and Schwartz, M. D.: 1997, Phenology in seasonal climates I, Backhuys Publishers, Leiden, the Netherlands, pp. 1-21.

Lieth, H.: 1974, Phenology and Seasonality Modelling, Berlin, Heidelberg and New York, SpringerVerlag, pp. 4-5.

Menzel, A. and Fabian, P.: 1999, 'Growing season extended in Europe', Nature 397, 659.

Menzel, A., Estrella, N., and Fabian, P.: 2001, 'Spatial and temporal variability of the phenological seasons in Germany from 1951-1996', Glob. Change Biol. 7, 657-666. 
Menzel, A., Jakobi, G., Ahas, R., Scheifinger, H., and Estrella, N.: 2003, 'Variations of the climatological growing season (1951-2000) in Germany compared with other countries', Int. J. Climatol. 23, 793-812.

Myneni, R. B., Keeling, C. D., Tucker, C. J., Asrar, G., and Nemani, R. R.: 1997, 'Increased plant growth in the northern high latitudes from 1981 to 1991', Nature 386, 698-702.

Parmesan, C. and Yohe, G.: 2003, 'A globally coherent fingerprint of climate change impacts across natural systems', Nature 421, 37-42.

Peñuelas, J. and Filella, I.: 2001, 'Responses to a warming world', Science 294, 793-794.

Peñuelas, J., Filella, I., and Comas, P.: 2002, 'Changed plant and animal life cycles from 1952 to 2000 in the Mediterranean region', Glob. Change Biol. 8, 531-544.

Root, T. L., Price, J. T., Hall, K. R., Schneider, S. H., Rosenzweig, C., and Pounds, A.: 2003, 'Fingerprints of global warming on wild animals and plants', Nature 421, 57-60.

Schwartz, M. D. and Reiter, B. E.: 2000, 'Changes in North American spring', Int. J. Climatol 20, 929-932.

Schwartz, M. D. and Chen, X.: 2002, 'Examining the onset of spring in China', Climate Research 21, $157-164$

Seemann, J., Chirkov, Y. I., Lomas, J., and Primault, B.: 1979, Agrometeorology, Berlin, Heidelberg and New York, Springer-Verlag, pp. 111-114.

Sha, W., Shao, X., and Huang, M.: 2002, 'Climate warming and its impact on natural regional boundaries in China in the 1980s', Sci. China, Ser. D 45, 1099-1113.

Scheifinger, H., Menzel, A., Koch, E., and Peter, Ch.: 2003, 'Trends of springtime frost events and phenological dates in Central Europe', Theor. Appl. Climatol. 74, 41-51.

Walther, G. R.: 2004, 'Plants in a warmer world', Perspectives in Plant Ecology, Evolution and Systematics 6, 169-185.

Walther, G. R., Post, E., Convey, P., Menzel, A., Parmesan, C., Beebee, T. J. C., Fromentin, J. M., Hoegh-Guldberg, O., and Bairlein, F.: 2002, 'Ecological responses to recent climate change', Nature 416, 389-395.

Wan, M.: 1986, Natural Phenological Calender in China, Science Press, Beijing, 421 pp (in Chinese).

Wan, M.: 1987, Natural Phenological Calender in China (Continued), Science Press, Beijing, 437 pp (in Chinese).

Zhang, F.: 1985, Phenology, China Meteorological Press, Beijing, 57-73 (in chinese).

Zhang, F. and Jiang, A.: 1996, 'A review of studies on the phenology in China', Phenology and seasonality 1, 71-78.

Zheng, J., Ge, Q., and Hao, Z.: 2002, 'Impacts of climate warming on plants phenophases in China for the last 40 years', Chinese Sci. Bull. 47, 1826-1831.

(Received 7 October 2004; Accepted 8 November 2005) 